\title{
CONFERÊNCIA LOCAL DE SAÚDE A PARTIR DO ITINERÁRIO DE PESQUISA DE FREIRE: RELATO DE EXPERIÊNCIA
}

\section{CONFERENCE OF LOCAL HEALTH FROM THE ITINERARY OF SEARCH FREIRE: EXPERIENCE REPORT}

\section{CONFERENCIA DE SALUD LOCAL DEL ITINERARIO DE BÚSQUEDA FREIRE: RELATO DE EXPERIENCIA}

Juliano de Amorim Busana ${ }^{1}$, Ivonete Teresinha Schulter Buss Heideman ${ }^{2}$, Águeda Lenita Pereira Wendhausen ${ }^{3}$, RESUMO

\author{
Daniele Delacanal Lazzari ${ }^{4}$
}

Objetivo: descrever a experiência da organização e realização de uma Conferência Local de Saúde, a partir de diálogos oriundos da realização de Círculos de Cultura em um Conselho Local de Saúde de um município do estado de Santa Catarina, Brasil. Método: relato de experiência oriundo de uma dissertação de mestrado que utilizou o Itinerário de Freire para o seu desenvolvimento, cuja coleta de dados foi realizada de junho a setembro de 2013. Resultados: apresentou-se o processo de planejamento, desenvolvimento e avaliação de cinco encontros alicerçados nos Círculos de Cultura de Freire, realizados com onze conselheiros que culminou em uma Conferência Local de Saúde. São apresentadas as expectativas, a avaliação dos participantes e suas reflexões sobre os resultados da pesquisa. Conclusão: apontam-se, ações de responsabilidade dos representantes envolvidos com a temática e evidencia a existência de um espaço em permanente construção de fortalecimento de estratégias de Promoção da Saúde e empoderamento.

Descritores: Participação comunitária; Estratégias; Conselhos de saúde; Conferências de saúde; Promoção da Saúde.

\begin{abstract}
Objective: to describe the experience of the organization and implementation of a Local Health Conference from dialogues arising from the realization of Culture Circles in a Local Health Council of a municipality in the state of Santa Catarina, Brazil. Method: experience report came from a dissertation that used the Route of Freire for its development, which data collection was carried out from June to September 2013. Results: presented the process of planning, development and evaluation of five grounded meeting in Freire culture circles, made with eleven members that culminated in a Local Health Conference. Expectations are.

\footnotetext{
${ }^{1}$ Enfermeiro, Mestre em Enfermagem, Programa de Pós-Graduação em Enfermagem, Universidade Federal de Santa Catarina (UFSC). Membro do Grupo de Pesquisas NEPEPS (Núcleo de Extensão e Pesquisa em Promoção da Saúde e Enfermagem). Florianópolis, SC, Brasil. E-mail: julianobusana @ hotmail.com.

2 Enfermeira, Doutora em Enfermagem em Saúde Pública. Professora Associada do Departamento de Enfermagem e Programa de Pós-Graduação em Enfermagem da UFSC. Líder do Grupo de Pesquisas NEPEPS (Núcleo de Extensão e Pesquisa em Enfermagem e Promoção da Saúde). Florianópolis, SC, Brasil. E-mail: ivonete.heidemann@ufsc.br.

${ }^{3}$ Enfermeira, Doutora em Enfermagem. Professora do Programa de Mestrado em Saúde e Gestão do trabalho e do curso de graduação em enfermagem da Universidade do Vale do Itajaí. E-mail: aguedalenita@ gmail.com.

${ }^{4}$ Enfermeira, Mestre em Educação. Doutoranda do Programa de Pós-Graduação em Enfermagem da UFSC. Membro do Grupo de Pesquisas EDEN (Educação em Enfermagem e Saúde). Florianópolis, SC, Brasil. E-mail: danielelazza@gmail.com.
} 
presented, the evaluation of the participants and their reflections on the search results Conclusion: point out: responsibility actions of the representatives involved in the subject and highlights the existence of a space in permanent construction strengthening promotion strategies of health and empowerment.

Descriptors: Consumer participation; Strategies, Health councils; Health conferences; Health promotion;

\section{RESUMEN}

Objetivo: Describir la experiencia de la organización y la ejecución de una Conferencia Local de Salud de los diálogos derivados de la realización de los Círculos de Cultura en un Consejo de Salud local de un municipio en el estado de Santa Catarina, Brasil. Método: relato de experiencia provenía de una disertación que utiliza la vía de Freire para su desarrollo, que la recogida de datos se llevó a cabo de junio a septiembre de 2013. Resultados: presentó el proceso de planificación, desarrollo y evaluación de cinco reunión a tierra en los Círculos de Cultura Freire, hecha con once miembros que culminaron en una Conferencia de Salud local. expectativas se presentan, la evaluación de los participantes y sus reflexiones sobre los resultados de la búsqueda. Conclusión: el punto es, las acciones de responsabilidad de los representantes involucrados en el tema y pone de manifiesto la existencia de un espacio en el fortalecimiento de las estrategias de promoción de la construcción permanente de la salud y la autonomía.

Descriptores: Participación comunitaria; Estrategias; Consejos de salud; Conferencias de salud; Promoción de la salud.

\section{INTRODUÇÃO}

A partir da Constituição de 1988 estabeleceu-se a participação da população na formulação de políticas públicas e o controle social das ações em todos os níveis, por meio de organizações representativas. Neste contexto, os Conselhos Gestores de Políticas Públicas surgiram como possibilidade de tornar a participação popular uma ferramenta para a gestão pública compartilhada entre Estado e sociedade por meio de representações governamentais e civis estabelecidas por mandato e normativamente reguladas. ${ }^{1}$
Por meio da assimilação das propostas da Reforma Sanitária e da $8^{\mathrm{a}}$ Conferência Nacional de Saúde na Constituição Federal de 1988, que posteriormente foram regulamentadas pela Lei $n^{\circ} 8.142 / 90$, as Conferências de Saúde ocorreram nas esferas municipal, estadual e nacional e constituíram-se em um dos requisitos formais para a descentralização dos serviços de saúde. Deste modo, as Conferências, juntamente com os Conselhos de Saúde, nas três esferas de governo, representam a consolidação da diretriz constitucional de participação da comunidade. $^{2}$ 
Os Conselhos Locais de Saúde (CLS) são estruturas públicas que se movimentam através da mobilização de profissionais da saúde e da população, buscando fiscalizar quaisquer ações desenvolvidas no âmbito da saúde dentro de certa área de abrangência. ${ }^{2}$

Os CLS estão vinculados à Estratégia de Saúde da Família (ESF) e compõem parte das ações do Conselho Municipal de Saúde (COMUSA). A ESF, por sua vez, surgiu objetivando reorganizar a prática assistencial, com ações de saúde centradas no núcleo familiar. ${ }^{3,4}$

O Itinerário de Pesquisa Freireano prevê que os Círculos de Cultura por meio de suas etapas que são: investigação temática, codificação e descodificação e desvelamento crítico, possam ser executados com uma quantidade menor e variável de participantes, por se tratar de um método dinâmico, versátil e que proporciona a aproximação entre pesquisadores e participantes da pesquisa, transformando o assunto de interesse do pesquisador também em interesse coletivo. O rigor epistemológico é assegurado, por meio de uma reflexão profunda e íntegra da realidade, desenvolvendo a autonomia do sujeito no processo. ${ }^{5}$
Foi no âmbito do CLS, espaço este que possibilitou a realização desta experiência, a realização do Círculo de Cultura, sendo este termo cunhado por Freire $^{6}$, indicando um espaço dinâmico de aprendizagem e troca de conhecimento, em que os participantes se reúnem no processo de educação para investigar temas de interesse do próprio grupo. Uma situaçãoproblema leva a uma reflexão acerca da própria realidade, para, na sequência, ser examinada e reconhecida em suas causas e potencialidades. ${ }^{6}$

Os Círculos de Culturas são momentos que se constituem por meio do exercício dialógico, com dimensões educativas e como uma atividade que subsidia o planejamento destes processos de forma participativa. Ao utilizar a abordagem metodológica do Círculo de Cultura se potencializa e sensibiliza para a consciência, o exercício plano da autonomia, além de estimular a participação como uma forma de empoderamento e emancipação dos indivíduos. $^{7}$

O Itinerário freireano dá ênfase ao diálogo, valoriza os saberes populares e favorece uma consciência crítica da realidade. ${ }^{8}$ A ideia de propor estratégias de educação em saúde a partir desta 
metodologia se deu pela necessidade de conhecer a realidade, mas principalmente, garantir o diálogo, a troca de experiências, a sensibilização e a participação, que culminassem em mobilização e empoderasse os indivíduos.

Freire $^{7}$ propõe o entendimento do ser humano como um ser que transforma a realidade pelo papel ativo que desempenha nela e com ela e, com seu trabalho, tem alterado, historicamente, o mundo natural de acordo com suas necessidades, mediando o processo de conhecimento, que é cultural.

Este relato tem como objetivo descrever a experiência da organização e realização de uma Conferência Local de Saúde, a partir de diálogos oriundos da realização de Círculos de Cultura em um dos oito CLS de um município do estado de Santa Catarina, Brasil.

\section{MÉTODO}

Trata-se de um relato de experiência oriundo de uma pesquisa que utilizou o Itinerário de Freire para o seu desenvolvimento e constitui parte de dissertação de mestrado apresentada ao Programa de Pós-graduação em Enfermagem da Universidade Federal de Santa Catarina, cuja coleta de dados foi realizada no período de junho a setembro de 2013. O local do estudo foi um CLS de um município do norte do Estado de Santa Catarina, em que as duas ESF existentes naquela comunidade atendem cerca de 2.300 famílias com aproximadamente 9.000 pessoas. $\mathrm{O}$ estudo foi aprovado pelo Comitê de Ética em Pesquisa da referida universidade, sob o protocolo $\mathrm{n}^{\mathrm{o}} 393.516$.

A seleção do Conselho participante deste estudo ocorreu com base nas informações coletadas junto ao presidente do Conselho Municipal de Saúde, optandose por aquele considerado o mais representativo e atuante no município. O número de participantes das reuniões do Conselho Local escolhido é variável, constituindo-se um grupo de 10 conselheiros (necessariamente na composição mínima de $70 \%$ de usuários e $30 \%$ de representantes das Unidades de Saúde, conforme regimento interno), quando da realização desta pesquisa. Dessa forma, as reuniões realizadas mensalmente possuem certa variação quanto ao número de presentes, não existindo formalmente número mínimo ou máximo de sujeitos para a ocorrência das reuniões mensais.

Como critério de inclusão dos sujeitos para este estudo, considerou-se: todos os presentes nas reuniões. Os sujeitos que não aceitassem assinar o Termo de 
Consentimento Livre e Esclarecido (TCLE) seriam excluídos.

Os Círculos de Cultura foram compostos por encontros com até 11 sujeitos, dentre usuários e profissionais da saúde, que favoreceram e fomentaram o diálogo como uma estratégia de comunicação efetiva, gerando inúmeros questionamentos sobre a realidade vivida por estes sujeitos no Conselho Local de Saúde. Os Círculos de Cultura geraram Temas para análise e constituíram-se em espaços de aprendizagem, promovendo a ação e a reflexão entre todos os envolvidos. ${ }^{14}$

Ao todo, desenvolveram-se cinco Círculos de Cultura, no período compreendido entre os meses de junho a setembro de 2013, com cerca de 2 horas de duração cada encontro.

\section{RESULTADOS}

Por meio dos diálogos ocorridos durante os Círculos de Cultura foram suscitadas reflexões que contribuíram com o CLS. A partir disto, efetivaram-se propostas pedagógicas que problematizaram os inúmeros desafios encontrados para o fortalecimento do SUS no município em que se deu o estudo e possibilitaram, igualmente, a construção de estratégias conjuntas para superações dos problemas. A partir dos Círculos delineouse uma proposta de realização da $\mathrm{I}^{\mathrm{a}}$ Conferência Local de Saúde, como materialização de um espaço permanente de discussões e socialização dos avanços obtidos a partir das demandas geradas pelos Conselhos. Deste modo, os Círculos de Cultura realizados culminaram com a referida Conferência, ocorrida no mês de outubro de 2013, cujos anseios subsistiam devido à necessidade de ampliação das discussões e aproximação dos Conselhos com o cotidiano das diversas localidades que estes representam.

\section{Círculos de Cultura como estratégia} metodológica para intervenção

Nos CLS, as atividades educativas em grupo constituem-se em importantes mecanismos de promoção da saúde, que por sua vez, podem ser entendidos como um necessário processo de empoderamento dos indivíduos e comunidades sobre os mais variados determinantes em saúde, favorecendo a problematização da realidade e conquistas de melhores condições de vida. ${ }^{9}$

Desta forma, a opção dos pesquisadores por esta forma de atividade educativa para compreensão da realidade, se deu em função não apenas dos 
significados atribuídos à metodologia freireana, mas também, por esta tratar-se de uma oportunidade profícua para a construção de uma relação baseada no diálogo entre pesquisadores e participantes da pesquisa. O referencial de Paulo Freire, apesar de ocupar uma posição paulatinamente sólida na área educacional, tem representado um desafio para a área da pesquisa e encontra-se em expansão, embora já se constitua como uma alternativa metodológica importante. ${ }^{10}$

\section{Descrição dos Círculos de Cultura}

O primeiro Círculo de Cultura consistiu no reconhecimento da realidade por parte dos pesquisadores e representantes (usuários e profissionais da saúde), em que as informações e discussões gerais acerca do CLS se efetivaram. Após apresentação formal da pesquisa e seus objetivos, obteve-se o consentimento formal dos presentes para participação, filmagem e gravação das reuniões.

No segundo Círculo de Cultura, procedeu-se à nova apresentação, pois havia novos participantes. Em seguida, as reflexões foram norteadas pelos questionamentos: quais são as práticas de participação no CLS, quais as dificuldades da participação no CLS e quais são as facilidades da participação no CLS? As discussões não evoluíram como esperado, pois havia outros assuntos em pauta. Desta forma, propôs-se o retorno dos questionamentos para a próxima reunião.

No segundo e terceiro Círculos de Cultura, deu-se continuidade aos já mencionados questionamentos, com o objetivo de reforçar a discussão em torno dos temas geradores a fim de fortalecê-los. Nestes círculos houve excelente participação dos presentes, gerando inúmeras discussões e reflexões sobre a realidade local.

O quarto Círculo de Cultura teve como objetivo codificar e descodificar os temas geradores levantados nas reuniões anteriores. Houve ampla participação dos presentes, acerca dos nove temas geradores, que foram selecionados para a discussão e desvelamento crítico. Desta forma, ao serem questionados quais eram as práticas de participação do CLS, os representantes elencaram que: 1) aprender sobre o conselho, 2) lutar por melhoria nas condições de vida da comunidade e 3) divulgar o CLS junto à comunidade eram as práticas consideradas mais importantes. Sobre as potencialidades da participação no CLS, apontaram 4) a possibilidade de 
exercício da cidadania; 5) a necessidade de constituição de um espaço educativo e 6) a intencionalidade de tomada de decisão que represente a coletividade.No que compete aos limites do CSL, citaram 7) o desconhecimento acerca das responsabilidades do conselho, 8) a exiguidade de participação da comunidade e 9) o descrédito da comunidade com as decisões tomadas no âmbito do Conselho.

O quinto Círculo de Cultura teve como objetivo desvelar os temas geradores levantados, codificados e descodificados nas reuniões anteriores. Foi amplamente discutida a questão da participação e o real papel do conselho e dos conselheiros, uma vez que, esta temática apareceu nas três questões levantadas nos círculos anteriores e que os próprios participantes elencaram como prioritárias na codificação. E com essa discussão foram sugeridas ações para melhorar suas participações e também da comunidade, instruindo e divulgando amplamente o CLS.

Dentre as estratégias surgidas dos diálogos, encontraram-se: utilização de ofícios para comunicação para com o poder executivo, legislativo e COMUSA, convites para os representantes de outras áreas da comunidade, convite para participação nas reuniões do CLS para os representantes do poder executivo e legislativo, que já participam frequentemente das reuniões da associação de moradores, caixa de sugestões para a comunidade expressar-se a respeito de suas necessidades em saúde, utilização de cartazes a serem distribuídos na comunidade para divulgar o CLS e os êxitos já conquistados até então, com o objetivo de favorecer a credibilidade e incentivar maior participação da comunidade, divulgação do CLS nas atividades religiosas, comuns na comunidade (missas e encontros festivos), palestras para a comunidade com a presença do presidente do COMUSA, para abordar questões relacionadas.

Desta forma, durante a etapa do desvelamento crítico, como uma das proposições dos presentes como forma de melhorar a participação dos conselheiros e da comunidade através de incentivo, informação e capacitação dos indivíduos e do coletivo, o presidente do Conselho, sugeriu a confecção de cartazes para espalhar na comunidade levando informações a respeito do Conselho e de suas experiências exitosas e convidar o presidente do COMUSA, para participar de uma reunião do CLS. 
Seguindo nesta linha de raciocínio uma das profissionais de saúde participantes do CLS, sugeriu emitir um ofício convidando o presidente do COMUSA para participar de uma reunião, devido ao seu grande conhecimento a respeito do Sistema Único de Saúde (SUS), dos Conselhos de Saúde com o intuito de realizar uma reunião ampliada, convidando assim, as lideranças da comunidade, diretoras dos colégios, comerciantes, etc., incentivando-os a participar do CLS.

Neste ínterim, o presidente do CLS propõe convidar os empresários da comunidade a participarem desta reunião, pois segundo ele, estes podem contribuir com o engrandecimento e melhorias do SUS, além de estimular a participação das lideranças comunitárias, que poderão influenciar as pessoas da comunidade devido a confiança que conquistaram.

Um dos participantes aponta que o COMUSA possui verba para financiar um encontro e que isto se torna um atrativo para a participação da comunidade. E é neste momento através do conjunto de ideias que surge a concepção de realizar uma Conferência Local de Saúde.

Desta forma, acordou-se uma data no mês de outubro entre os presentes. Mediante tal deliberação, foram emitidos dois Ofícios, um para convidar o Presidente do COMUSA, outro para convidar o Coordenador Técnico do Departamento de Planejamento e Auditoria, e o médico atuante na ESF da comunidade de onde o CLS faz parte. Ainda em outubro, em reunião ordinária do CLS, discutiu-se como pauta o retorno em relação aos convites encaminhados, a distribuição das incumbências de cada conselheiro quanto à divulgação e suas respectivas responsabilidades para a execução da Conferência e a decisão sobre o nome da Conferência, então denominada "A saúde, um bem que se quer: a participação da sociedade para a melhoria do SUS".

Com isso, foram confeccionados os convites individuais para a comunidade e cartazes para distribuição na Unidade de Saúde da Família e em toda a área adstrita do CLS. Na programação constavam uma sessão de abertura, conferências, debate e coquetel de encerramento. Estas informações foram divulgadas nas redes sociais com o objetivo de atingir um maior número de pessoas.

Ao final de cada Círculo de Cultura foi feita uma avaliação parcial, oportunidade em que cada participante pôde manifestar-se a respeito de todo o 
processo. Na última sessão realizou-se a avaliação final, por meio de relato livre acerca dos Círculos, seu processo e seu produto.

\section{Conferência Local de Saúde}

O caráter democrático das decisões fomentado pela participação da sociedade civil nas atividades próprias da administração pública toma forma através dos Conselhos de Saúde e favorece a realização de intervenções que contribuam para melhor qualidade de vida e respeitem as características culturais de cada comunidade. A realização de uma Conferência de Saúde situa-se no âmbito de fazer cumprir a Lei 8142/90, oportunizando um espaço democrático de aprendizado e promoção da saúde. Faz parte deste processo, o estímulo à participação da comunidade e dos trabalhadores do SUS em propostas que visem melhorar a qualidade dos serviços de saúde. ${ }^{11}$

No dia 31 de outubro de 2013, realizou-se, então, a $1^{\text {a }}$ Conferência Local de Saúde, intitulada "A saúde, um bem que se quer: a participação da sociedade para a melhoria do SUS", como estratégia empoderadora e estimulante para os conselheiros e a comunidade, com o objetivo de aumentar e de qualificar a participação popular na comunidade do CLS. Esta conferencia contou com a presença de 57 pessoas da comunidade no Salão Paroquial da igreja localizada na comunidade a que pertence o CLS. Participaram moradores da comunidade, colaboradores da Unidade de Saúde da Família, conselheiros e palestrantes. Discorreu-se a respeito da importância da presença de todos e do reforço para a participação popular e o controle social.

Um profissional da saúde palestrou a respeito das funções da ESF no SUS como, por exemplo: prestar, na unidade de saúde da família e no domicílio, assistência integral, contínua, com resolubilidade e boa qualidade às necessidades de saúde da população adscrita; intervir sobre os fatores de risco aos quais a população está exposta; contribuir para a democratização do conhecimento do processo saúde/doença, da organização dos serviços e da produção social da saúde; e fazer com que a saúde seja reconhecida como um direito de cidadania e, portanto, expressão da qualidade de vida. Estimular a organização da comunidade para o efetivo exercício do controle social. Posteriormente apresentou um breve resumo do perfil epidemiológico da 
comunidade, baseado nas informações retiradas dos Sistemas de Informação do Ministério da Saúde.

O Coordenador Técnico do Departamento de Planejamento e Auditoria da Secretaria Municipal de Saúde, dialogou a respeito da participação popular no Brasil através da história e nos dias atuais, como movimentos políticos do tipo a luta pela anistia ampla, geral e irrestrita, a reforma sanitária, as Diretas Já, a luta pela convocação de uma Assembleia Nacional Constituinte a qual culminou na criação do SUS e nas Leis complementares que garantiram e institucionalizaram a participação popular através dos Conselhos de Saúde.

Por fim o Presidente do COMUSA difundiu outras informações a respeito do SUS e da Participação Popular, dialogando a respeito do funcionamento e do efetivo papel dos Conselhos de Saúde nas suas várias instâncias e da importância da participação popular para que haja efetividade e legitimidade nas reinvindicações propostas pela população e assim sendo, acatada pela gestão pública.

Para finalizar a Conferência o presidente do CLS reforçou a importância da construção e manutenção destes espaços de participação popular, com o intuito de refletir e deliberar estratégias para o progresso na qualidade de vida da comunidade.

Em reunião do CLS posterior a Conferência, discutiu-se alguns aspectos relacionados à Conferência, como a grande participação dos membros da comunidade, como também a grande participação, por meio de questionamentos realizados aos palestrantes. Com isso, a Conferência foi avaliada pelos conselheiros como de grande sucesso e valor, ao ponto que, fomenta a participação da comunidade, uma vez que, os indivíduos passam a conhecer e acreditar nas potencialidades que o CLS possui para colaborar expressivamente com o desenvolvimento comunitário.

A Conferência constituiu-se em um primeiro passo a ser dado para a efetivação da melhoria do SUS através da participação popular e do controle social, estimulando a participação de todos nas reuniões do CLS e do COMUSA. Com isso ficou-se estabelecido que o segundo passo, será dar continuidade as ações de divulgação e convocação da comunidade para a participação efetiva no CLS e que no ano 2014 uma nova Conferência Local de Saúde será delineada e executada para manter ativo este processo de fomento à 
participação popular e o desenvolvimento das práticas participativas.

\section{CONSIDERAÇÕES FINAIS}

Ao utilizar o Itinerário de Pesquisa de Freire, por meio de ações dialógicas libertadoras que constituem os Círculos de Cultura, este proporcionou aos conselheiros participantes desta pesquisa discutir e refletir a respeito da realidade da comunidade em relação a suas práticas participativas, suas potencialidades e suas fragilidades para participarem do CLS.

Freire em sua visão político/filosófica, revela que a vida humana tem uma significação, enquanto razão de ser, e está além das relações de opressão existentes na comunidade. Esta visão indica um compromisso emancipatório e da libertação da comunidade, sendo que esta forma de pensar/agir pode colaborar com o entendimento do significado da participação popular.

Considera-se positivo a reflexão efetuada nos Círculos de Cultura, visto que culminou na realização da I Conferência Local de Saúde. "A saúde, um bem que se quer: a participação da sociedade para a melhoria do SUS", como estratégia empoderadora e estimulante para os conselheiros e a comunidade, com o objetivo de aumentar e de qualificar a participação popular na comunidade do CLS estudado. Esta conferencia constituiuse num espaço importante de diálogo entre os participantes, com identificacao dos determinantes de saude que interferiam na qualidade de vida da comunidade do estudo. A metodologia proposta oportunizou o dialogo entre os membros participantes e empoderou-os a participacao para que em conjunto discutissem novos caminhos para o CLS.

A importância da utilização da I Conferência Local de Saúde como ferramenta empoderadora está no fato dos Conselhos e das Conferências constituírem-se em locais que possibilitam a construção da democracia, espaços que colaboram para o fortalecimento do SUS e a melhoria dos serviços ofertados à comunidade e consequentemente melhoria da qualidade de vida.

Com isso ressalta-se a relevância da utilização do Itinerário de Pesquisa de Freire que proporcionou a discussão e a reflexão necessária para realização da conferência. A reflexão sucedida nos Círculos de Cultura não se deu de maneira descontinuada ao desvelamento dos temas investigados, mas conduziu para ações que 
favoreceram a transformação do status $q u o$, transcendeu a realização da pesquisa e dos Círculos de Cultura, culminando na mudança da realidade da comunidade, a partir da execução de um ato refletido anteriormente.

Como potencialidades destacamos a utilização desta metodologia de pesquisa nos Círculos de Cultura, como possibilidade de diálogos e reflexão entre os participantes. Somente podemos aprofundar os valores, desejos e prioridades de uma comunidade quando a ouvimos. Como limites, destaca-se ainda o descredito da população a participação nos conselhos, há necessidade de um constante estímulo, visto que historicamente discutem-se a superfície dos problemas, adotando soluções livres e desconectadas da realidade, são assumidos valores e prioridades que, na verdade, não correspondem aqueles da sociedade envolvida.

\section{REFERÊNCIAS}

1. Brasil. Lei $n^{\circ} 8.142$ de 28 de dezembro de 1990. Dispõe sobre a participação da comunidade na gestão do Sistema Único de Saúde (SUS) e sobre as transferências intergovernamentais de recursos financeiros na área da saúde e dá outras providências. Diário Oficial da República Federativa do Brasil, 28 dez 1990.

2. Souza AV, Krüger TR. Participação social no sus: proposições das conferências sobre o conselho local de saúde. Rev. saúde pública. 2010; 3(1):80-96.

3. Mielke FB, Cossetin A, Olschowsky A. O conselho local de saúde e a discussão das ações de saúde mental na estratégia saúde da família. Texto \& contexto enferm. 2012; 21(2):387-94.

4. Franco ECD. A estratégia de saúde da família na perspectiva do usuário. Rev. Enferm UFSM. 2012; 2(1):49-58.

5. Durand MK, Heidemann ITSB. Promoção da autonomia da mulher na consulta de enfermagem em saúde da família. Rev. Esc. Enferm. USP. 2013; 47(2):288-95.

6. Freire P. Pedagogia da esperança. 15 a ed. Rio de Janeiro (RJ): Paz e Terra; 2007.

7. Educação como prática de liberdade. $26^{\mathrm{a}}$ ed. Rio de Janeiro (RJ): Paz e Terra; 2002.

8. Monteiro EMLM, Vieira NFC. Educação em saúde a partir de círculos de cultura. 2010; 63(3):397-403.

9. Rumor PCF, Berns I, Heidemann ITSB, Helena L. A promoção da saúde nas práticas educativas da saúde da família. Cogitare enferm. 2010; 15(4):674-80.

10. Heidemann ITSB, Wosny AM, Boehs AEB. Promoção da Saúde na Atenção Básica: Investigação Temática de Paulo Freire. Ciênc. saúde coletiva. 2014; 19(8):3553-9.

11. Krüger TR, Lemke AP, Dias DN, Nunes MLA, Meggiato JR, Finger SJ, et al. A organização e a dinâmica participativa dos segmentos sociais nas conferências municipais de saúde. Emancipação. 2012; 12(1):119-130.

Recebido em: 11/09/2015.

Aprovado em: 30/06/2016.

Publicado em: 31/07/2016. 